\title{
Game Analysis of Strategic Partner Selection of Chinese and Foreign Technology Alliance
}

\author{
Xiaohua Sun \\ Department of Economics, Dalian University of Technology \\ No. 2 Ling Gong Road, Gan Jingzi District, Dalian 116024, China \\ Tel: 86-411-8470-7221 E-mail:sxh_dut@sina.com \\ $\mathrm{Lin} \mathrm{Hu}$ \\ Department of Economics, Dalian University of Technology \\ No. 2 Ling Gong Road, Gan Jingzi District, Dalian 116024, China \\ Tel: 86-411-8470-7221_E-mail: jacky97@163.com
}

Project supported by the National Natural Science Foundation of China (Grant No.70803006).

\begin{abstract}
This paper makes a discussion on the strategic partnership selection problem of technology alliance using the methods of game theory. We found the complete information dynamic game through backward induction which shows that when a companies have set up a strategic alliance with foreign manufacturers, it will select the interfere strategy to prevent an alliance between the other Chinese companies and transnational corporation, therefore, the optimal strategy of the latter is to maintain the status quo, and give up the motives of the strategic alliances.
\end{abstract}

Keywords: Dual oligopoly, Strategic Technology Alliance, Power market, Complete information dynamic game

\section{Introduction}

At present, the competition has become increasingly intense, which poses more challenges for the competition of enterprises and their development. Since 1990's, many companies have a strategic adjustment to large-scale confrontation from mutual competition, and they set up the strategic alliance between each other, among which more strategic technology alliance happened in high-tech fields.

According to the relevant data, over $90 \%$ of the world's largest 150 transnational corporations have set up all kinds of strategic alliances with other companies, in which R\&D alliances has become an important source of technology in multinationals. Such as IBM, Toshiba, Siemens have form the tripartite alliance, and they get a joint development of new type of DRAM computer chips; Boeing Company and Japan's Mitsubishi Heavy Industries form an alliance to develop Boeing 767 wide-body civilian jetliner, both them are a classic example of strategic alliances. In the face of intense domestic competition, our company may be carry out cooperate with foreign companies, and foreign companies are also seeking the chance to enter the Chinese market. Strategic alliance as one of modern enterprise organization system innovations has become an important means of modern enterprise which get sustainable competitive advantage, called "the most important organizational innovation in end of the 20th century."

\section{Basic hypothesis}

There are two oligopoly firms A, B in Chinese nuclear power market. For the current market, as both sides hope to expand the market for investment, while the U.S. Westinghouse and France AREVA are full of expectations on China's nuclear power market, and want to cooperate with the monopoly, we assume that AREVA act X, Westinghouse is Y. The two manufacturers use the same equipment, technical level, that is, marginal cost and monopoly price is the same in the balance market, for two-oligopoly firms A and B.

When monopoly output is 1 , and A, B is co-operation, two manufacturers carve up the market through agreement; receive one-half of product market respectively. Maintaining such estate is the optimal strategy in the long game for the both sides, so the two sides will maintain the monopoly price and output, and prevent the entry of new firms through technical blockade, A, B get the conspiracy of

silence. Assume that cost function is $c(Q)$ for each monopoly manufacturers, the revenue for monopoly manufacturers is $R(Q)=P(Q) Q, P(Q)=a-b(Q)$, and the firm's profits function $\pi=R(Q)-C(Q)$.

Manufacturers face two choices, producing on their own or co-producing with foreign companies, when they choose to 
product on their own, assuming that the output of the two companies is $q_{1}, q_{2}$ respectively, the cost is $c_{1}, c_{2}$, prices is $p_{1}=p_{2}$ at this time for manufacturers, the manufacturers A, B's profits are:

$$
\begin{aligned}
& \pi_{1}=\left[a-b\left(q_{1}+q_{2}\right)\right] q_{1}-c_{1} q_{1} \\
& \pi_{2}=\left[a-b\left(q_{1}+q_{2}\right)\right] q_{2}-c_{2} q_{2}
\end{aligned}
$$

Assume that companies $\mathrm{A}, \mathrm{B}$ have the same production costs $c_{1}=c_{2}$, then according to conditions of profit maximization:

$$
\begin{aligned}
& \frac{\partial \pi_{1}}{\partial q_{1}}=0 \\
& \frac{\partial \pi_{2}}{\partial q_{2}}=0
\end{aligned}
$$

The production of maximize profit for two companies is

$$
q_{1}=\frac{a-2 c_{1}+c_{2}}{3 b}, q_{2}=\frac{a-2 c_{2}+c_{1}}{3 b}
$$

Because $c_{1}=c_{2}$, then:

Profit of two manufacturers at this time is:

$$
q_{1}=q_{2}=\frac{a-c_{1}}{3 b}
$$

\section{Establishment of game model}

$$
\pi_{1}=\pi_{2}=\frac{\left(a-c_{1}\right)^{2}}{9 b}
$$

When firm A cooperate with firm $\mathrm{X}$, the cost change from $c_{1}$ to $c_{1}^{1}$, and $c_{1}^{1}<c_{1}=c_{2}$, Profit of two manufacturers at this time is:

According to conditions of profit maximization:

$$
\begin{aligned}
& \pi_{1}^{1}=\left[a-b\left(q_{1}+q_{2}\right)\right] q_{1}-c_{1}^{1} q_{1} \\
& \pi_{2}^{1}=\left[a-b\left(q_{1}+q_{2}\right)\right] q_{2}-c_{2} q_{2}
\end{aligned}
$$

The production of two companies is:

$$
\begin{aligned}
& \frac{\partial \pi_{1}^{1}}{\partial q_{1}}=0 \\
& \frac{\partial \pi_{2}^{1}}{\partial q_{2}}=0
\end{aligned}
$$

$$
q_{1}^{1}=\frac{a-2 c_{1}^{1}+c_{2}}{3 b}, q_{2}^{1}=\frac{a-2 c_{2}+c_{1}^{1}}{3 b}
$$

Profit of two manufacturers at this time is:

$$
\pi_{1}^{1}=\frac{\left(a-2 c_{1}^{1}+c_{2}\right)^{2}}{9 b} \pi_{2}^{1}=\frac{\left(a-2 c_{2}+c_{1}^{1}\right)^{2}}{9 b}
$$

Because of $c_{1}^{1}<c_{1}$, then:

$$
q_{1}^{1}>q_{1}, \pi_{1}^{1}>\pi_{1}, c_{1}^{1}<c_{2} \text {, so } q_{2}^{1}<q_{2}, \pi_{2}^{1}<\pi_{2}
$$

In the game equilibrium, firms $\mathrm{A}$ choose to co-operate with foreign companies $\mathrm{X}$ as a result of, the cost decline and profits are increasing, the production and profits of companies B decline. But at the same time, a manufacturer B may not be reconciled to the original market balance has been broken, and it may choose to cooperate with Westinghouse. Because A just get the advantage by establishing a strategic alliance, of course, it will carry out a series of obstructionist behavior to prevent B set up a strategic alliance with $\mathrm{Y}$, this strategic game can be seen as a is a complete information dynamic game .

Insert Figure1 Here

When Equilibrium in the game, because firm A cooperates with foreign companies $\mathrm{X}$, the cost is declining and the profits are increasing, and companies B's profits and production are declining. But at the same time, firm B is not reconciled to the original market balance has been broken, so it may choose to Westinghouse that vendors $\mathrm{Y}$ to cooperate. A face just established a strategic alliance advantage, of course, it should takes a series of obstructionist behavior for that B cooperates with $\mathrm{Y}$, which can be seen as a strategic game is a dynamic game of incomplete information. 
We assume that firm A first decision-making,firm B in the observation of the selection decision-making. We assume process for the entire game is a two-stage dynamic game of incomplete information. Equilibrium outcome is a subgame perfect Nash equilibrium. When firm A takes a series of obstructionist behavior, Cost set $c_{1}^{2}$, Which $c_{1}^{2}>c_{1}$, firm $\mathrm{B}$ can be taken at this time cooperated with $\mathrm{Y}$ to deal with the conduct of firm A, due to the obstruction of firm $\mathrm{A}$, firm $\mathrm{B}$ cost turn into $c_{2}^{2}>c_{2}$, and assumption of $\frac{c_{1}^{2}-2 c_{2}^{2}}{c_{1}^{1}-2 c_{2}}>1$, so the profit of firm A and B are:

In accordance with manufacturers to maximize their profits:

$$
\begin{aligned}
& \pi_{1}^{2}=\left[a-b\left(q_{1}^{2}+q_{2}^{2}\right)\right] q_{1}^{2}-c_{1}^{2} q_{1}^{2} \\
& \pi_{2}^{2}=\left[a-b\left(q_{1}^{2}+q_{2}^{2}\right)\right] q_{2}^{2}-c_{2}^{2} q_{2}^{2}
\end{aligned}
$$

The profits of firm $\mathrm{A}$ and $\mathrm{B}$ are:

$$
\begin{aligned}
& \frac{\partial \pi_{1}^{2}}{\partial q_{1}^{2}}=0 \\
& \frac{\partial \pi_{2}^{2}}{\partial q_{2}^{2}}=0
\end{aligned}
$$

$$
\pi_{1}^{2}=\frac{\left(a-2 c_{1}^{2}+c_{2}^{2}\right)^{2}}{9 b}, \pi_{2}^{2}=\frac{\left(a-2 c_{2}^{2}+c_{1}^{2}\right)^{2}}{9 b}
$$

Because $c_{1}^{2}>c_{1}$, so $\pi_{1}^{2}<\pi_{1}<\pi_{1}^{1}$, also because $c_{2}^{2}>c_{2}, \frac{c_{1}^{2}-2 c_{2}^{2}}{c_{1}^{1}-2 c_{2}}>1$, there are $\pi_{2}^{2}<\pi_{2}^{1}<\pi_{2}$

When firms do not take the B and Y co-operation, the absence of firm A for the firm B doesn't cooperate with Y to pay the cost of blocking, so the profits of firm A is $\pi_{1}^{1}$, as a result of firm B doesn't cooperate with the Y, and its profit $\pi_{2}^{1}$ When firm A take the acquiescence of acts, when firm B cooperates with the Y, that is, firm A, firm B with X, Y to carry out co-operation, the costs are reduced $c_{1}^{*}, c_{2}^{*}$ and $c_{1}^{*}=c_{2}^{*}<c_{1}$, now firms A, B's profits are as follows:

Profit maximization:

$$
\begin{aligned}
& \pi_{1}^{*}=\left[a-b\left(q_{1}^{*}+q_{2}^{*}\right)\right] q_{1}^{*}-c_{1}^{*} q_{1}^{*} \\
& \pi_{2}^{*}=\left[a-b\left(q_{1}^{*}+q_{2}^{*}\right)\right] q_{2}^{*}-c_{2}^{*} q_{2}^{*}
\end{aligned}
$$

So

$$
\begin{aligned}
& \frac{\partial \pi_{1}^{*}}{\partial q_{1}^{*}}=0 \\
& \frac{\partial \pi_{2}^{*}}{\partial q_{2}^{*}}=0
\end{aligned}
$$

So

$$
q_{1}^{*}=\frac{a-2 c_{1}^{*}+c_{2}^{*}}{3 b}, q_{2}^{*}=\frac{a-2 c_{2}^{*}+c_{1}^{*}}{3 b}
$$

And also $q_{1}^{*}=q_{2}^{*}$ so the profits are $\pi_{1}^{*}=\pi_{2}^{*}=\frac{\left(a-c_{1}^{*}\right)^{2}}{9 b}$.

When firm A take the acquiescence of acts, and the firm B do not cooperate with the Y, then the profit of firm A is $\pi_{1}^{1}$, the profit of firm B is $\pi_{2}^{1}$.

This is a perfect information game, Structure of the game's strategic statements, the strategy space of firm A is $S_{A}=$ \{obstruction, acquiescence $\}$, there are four pure strategy for firm B, so the strategy space of firm B is $S_{A}=\{$ (obstruct, cooperate with $\mathrm{Y}$ ),(obstruction, to maintain the status quo),(acquiescence, cooperate with $\mathrm{Y}),($ obstruction, to maintain the status quo) $\}$. The following table is the game of strategic form representation.

\section{Insert Table 1 Here}

From the above analysis, the above analysis of the game is a two-stage game of perfect information, we use backward induction method to solve the reverse subgame perfect Nash equilibrium: in the second phase, the firm B is the optimal action rules: (acquiescence, cooperate with $\mathrm{Y}$ ), that is, if firm choose $\mathrm{A}$ in the first phase of the obstruction in the second stage firms choose B to maintain the status quo, if the firms choose A in the first stage of the acquiescence of, B in the second phase of selection and Y co-operation. Because firms will be in the first stage A to B in the forecast will be the second phase of operations in accordance with this rule, A in the first stage is the optimal choice of "obstruction."

\section{Conclusion}

In this paper, the use of incomplete information dynamic game model, discussed the Two-oligopoly firms the choice of strategic alliance. The following conclusions to be when a firm has been set up with foreign firms the case of strategic alliance, would choose to block the strategy to prevent another firm alliances with other multinational firms, which the 
optimal strategy is to maintain the status quo. However, the actual operation of the process of firm alliances is much more complex. In this paper, Union and only firms the choice of partners have done a preliminary study, in this regard need to be further in-depth analysis.

\section{References}

PAN, S Q. (2005). Technology spillovers oligopoly cases the efficiency of enterprise cooperation and innovation Game Analysis Business Study, (9).

PARK, SH and ZHOU, DS. (2005). Firm Heterogeneity and Competitive Dynamics in Alliance Formation. Academy of Management Review, 30 (3):531-554.

QIAN, H T. (2008). Dynamic alliance partners with the choice of game analysis Journal of Xi'an University of Science and Technology, (4).

ZHANG, W Y. (2004). Game Theory and Information Economics. shanghai: Shanghai People's Publishing House.

Table 1. The game of strategic form representation of firm A and B

\begin{tabular}{|c|c|c|c|c|c|}
\hline \multicolumn{2}{|c|}{} & \multicolumn{4}{|c|}{ Firm B } \\
\cline { 2 - 5 } \multicolumn{2}{c|}{} & $(\mathrm{C}, \mathrm{C})$ & $(\mathrm{C}, \mathrm{K})$ & $(\mathrm{K}, \mathrm{C})$ & $(\mathrm{K}, \mathrm{K})$ \\
\hline \multirow{3}{*}{ Firm A } & obstruction & $\pi_{1}^{2}, \pi_{2}^{2}$ & $\pi_{1}^{2}, \pi_{2}^{2}$ & $\pi_{1}^{1}, \pi_{2}^{1}$ & $\pi_{1}^{1}, \pi_{2}^{1}$ \\
\cline { 2 - 6 } & acquiescence & $\pi_{1}^{*}, \pi_{2}^{*}$ & $\pi_{1}^{1} \pi_{2}^{1}$ & $\pi_{1}^{*} \pi_{2}^{*}$ & $\pi_{1}^{1} \pi_{2}^{1}$ \\
\hline
\end{tabular}

Notes: $\mathrm{C}$ indicates cooperate with $\mathrm{Y}, \mathrm{K}$ indicates to maintain the status quo.

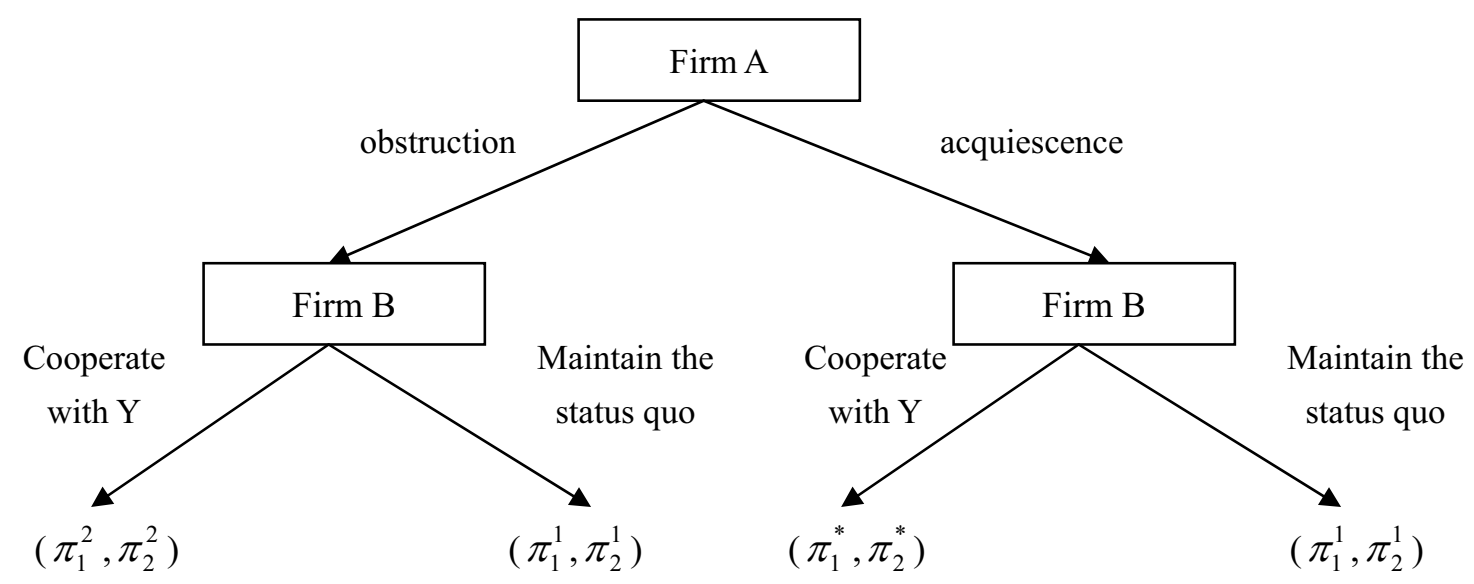

Figure 1. Firms A and B of the dynamic game 